Volume 2 Nomor 1 halaman 1-8

ISSN: 2089-6026

\title{
Pengukuran Kinerja Spam Filter Menggunakan Graham's Nä̈ve Bayes Classifier
}

\section{Measuring Performance of Spam Filter using Graham's Naive Bayes Classifier}

\author{
JULIO ADISANTOSO*, WILDAN RAHMAN
}

\begin{abstract}
Abstrak
Email spam telah menjadi masalah utama bagi pengguna dan penyedia jasa Internet. Pendekatan heuristic telah dilakukan untuk menyaring spam seperti black-listing atau rule-based filtering, namun hasilnya kurang memuaskan sehingga pendekatan berbasis konten (content-based filtering) menggunakan pengklasifikasi naïve Bayes lebih banyak digunakan saat ini. Penelitian ini bertujuan membandingkan pengklasifikasi naïve Bayes multinomial yang menggunakan atribut boolean dengan versi Graham, dan juga membandingkan kinerja dari dua metode untuk data latih, yaitu train-everything (TEFT) dan train-on-error (TOE). Hasil evaluasi menunjukkan bahwa naïve Bayes multinomial memiliki kinerja lebih baik dibanding versi Graham. Di samping itu, metode data latih menggunakan TEFT dapat meningkatkan akurasi model klasifikasi dibanding metode TOE.
\end{abstract}

Kata kunci: filter spam, naïve Bayes, metode training

\begin{abstract}
Spam email has become a major problem for Internet users and providers. After several failed attempt to filter spam based on heuristic approach such as black-listing or rule-based filtering, content-based filtering using naïve Bayes classifier has become the standard for spam filtering today. However, the naive Bayes classifier exists in different forms. This research aims to compare two different forms of naïve Bayes which are multinomial naive Bayes using boolean attribute and Graham version of nä̈ve Bayes which is popular among several commercial and open source spam filter applications. This research also compares performace of two different methods for data trainings which are train-everything (TEFT) and train-on-error (TOE). Finally, this research attempts to identify several hard-to-classify emails. The evaluation result showed that multinomial nä̈ve Bayes had better performance compared to Graham nä̈ve Bayes. The result also showed that TEFT successfully outperforms TOE in term of accuracy.
\end{abstract}

Keywords: spam filter, naïve Bayes, training method

\section{PENDAHULUAN}

Pemanfaatan teknologi jaringan Internet yang semakin meningkat intensitasnya dewasa ini berdampak besar pada metode pengiriman surat. Jalur fisik yang semula menjadi pilihan semakin ditinggalkan dan digantikan oleh jalur pengiriman elektronik dalam bentuk electronic mail atau biasa disebut dengan email. Berbagai macam keunggulan yang dimiliki oleh email ternyata banyak disalahgunakan untuk mengirimkan pesan berbau komersial secara massal.

Spam adalah pesan atau email yang "tidak diinginkan" oleh penerimanya dan dikirimkan secara massal. Makna "tidak diinginkan" di sini memiliki arti pihak pengirim tidak mendapatkan izin untuk mengirimkan pesan tersebut dari pihak penerima. Makna "dikirimkan secara massal" berarti pesan tersebut merupakan bagian dari sekumpulan pesan yang memiliki isi yang sama atau sejenis dan dikirimkan sekaligus dalam jumlah besar (Spamhaus 2009). 
Berbagai upaya telah dilakukan untuk mengatasi permasalahan spam. Pada mulanya proses penyaringan email spam dilakukan dengan pendekatan rule-based. Email dikategorikan sebagai spam menurut aturan-aturan tertentu seperti kemunculan kata, alamat pengirim, dan struktur header. Pendekatan ini dalam praktiknya kurang efektif dan memiliki tingkat false positive yang tinggi. Selain rule-based, metode spam-filtering yang banyak digunakan di masa lalu adalah server blacklist dan signature-based filtering (Graham 2003).

Pendekatan berbasis content statistic (menggunakan metode Naïve Bayes) untuk menyaring pesan spam pertama kali diteliti oleh Pantel dan Lin (1998) dan berhasil mencapai tingkat akurasi $92 \%$ dengan tingkat false positive sebesar $1.16 \%$. Teknik serupa juga digunakan oleh Sahami et al. (1998) meskipun kinerjanya tidak setinggi filter spam yang dirancang oleh Pantel dan Lin (1998).

Graham (2002) membahas teknik spam-filtering menggunakan metode pengklasifikasi naïve Bayes (NB) dengan pendekatan yang cukup berbeda jika dibandingkan dengan metode pengklasifikasi naïve Bayes pada umumnya. Metode ini diklaim berhasil mencapai tingkat akurasi sebesar $99.95 \%$ dengan false positive sebesar $0.05 \%$. Kinerja yang cukup tinggi ini membuat metode content-based filtering semakin banyak digunakan dalam aplikasi filter spam (Yerazunis 2004).

Penelitian ini menguji dua model dari teknik klasifikasi NB, yaitu NB multinomial dengan atribut boolean dan NB Graham. Penelitian ini juga menguji dua metode training yang digunakan pada filter spam. Lebih lanjut, penelitian ini membahas komponen pendukung yang digunakan dalam pembuatan filter spam seperti teknik pemrosesan email, pemilihan fitur, dan tokenisasi.

\section{METODE}

Penelitian ini terdiri atas empat tahap, yaitu pengumpulan data, pengujian metode training, pengujian metode klasifikasi, dan analisis kesalahan klasifikasi. Untuk metode training, terdapat dua macam metode yang diuji, yaitu training everything (TEFT) dan training on error (TOE). Masing-masing metode training diduga memiliki kinerja yang berbeda sehingga dilakukan pengujian untuk menentukan metode training mana yang memiliki kinerja yang lebih baik.

Pada metode TEFT, seluruh email yang masuk akan dilatih tanpa memperhatikan kebenaran hasil klasifikasinya. Kelebihan dari metode ini adalah sekumpulan data dalam filter spam yang akan terus menyesuaikan nilainya sesuai dengan email yang diterimanya. Sebagai contoh, jika pengguna berlangganan mailing-list tertentu, filter akan segera mengenali tokentoken di dalamnya sebagai bagian dari kelas ham. Sedangkan pada metode TOE, email hanya akan dimasukkan ke dalam proses training jika terjadi kesalahan klasifikasi. Kelebihan metode TOE idalah proses training hanya dilakukan seperlunya sehingga menghemat sumber daya, seperti proses disk-writing yang lambat. Metode TOE juga menyimpan lebih sedikit token sehingga dapat menghemat ruang penyimpanan.

Metode klasifikasi yang diuji terdiri atas dua model NB, yaitu Bayes multinomial dengan atribut boolean dan metode Bayes Graham. Bayes multinomial dengan atribut boolean hampir sama dengan Bayes multinomial yang menggunakan atribut frekuensi token atau term frequency $(\mathbf{t f})$, termasuk juga proses pendugaan nilai peluang suatu token ke-i $\left(\boldsymbol{t}_{\boldsymbol{i}}\right)$ dalam kelas spam $\boldsymbol{S}$, yaitu $\mathbf{P}\left(\boldsymbol{t}_{i} \mid \boldsymbol{S}\right)$. Perbedaannya terletak pada atribut yang digunakan, yaitu bernilai boolean. Pada atribut boolean, token yang muncul berulang kali tetap dianggap sebagai satu kemunculan untuk setiap dokumennya. Schneider (2004) dalam penelitiannya menunjukkan bahwa Bayes multinomial akan memiliki kinerja yang lebih baik jika atribut frekuensi token digantikan dengan atribut boolean.

Graham (2002) menggunakan pendekatan yang berbeda dalam mengimplementasikan naïve Bayes. Jika pada metode sebelumnya digunakan pendugaan nilai $\mathbf{P}\left(\boldsymbol{t}_{\boldsymbol{i}} \mid \boldsymbol{S}\right)$ untuk 
mendapatkan peluang suatu email masuk ke dalam kelas spam, metode Bayes Graham menggunakan pendugaan nilai $\mathbf{P}\left(\boldsymbol{S} \mid \boldsymbol{t}_{\boldsymbol{i}}\right)$ untuk menghitung peluang suatu email masuk ke dalam kategori spam jika diketahui email tersebut mengandung token $\boldsymbol{t}_{\boldsymbol{i}}$, yaitu:

$$
\mathrm{P}\left(\mathrm{S} \mid \mathrm{t}_{\mathrm{i}}\right)=\frac{\frac{\mathrm{f}_{\text {is }}}{\mathrm{n}_{\mathrm{s}}}}{\frac{\mathrm{fis}_{\mathrm{is}}}{\mathrm{n}_{\mathrm{s}}}+\frac{1 \mathrm{ih}}{n_{\mathrm{h}}}}
$$

dengan $f_{\text {is }}$ dan $f_{\text {ih }}$ berturut-turut adalah banyaknya email pada kelas spam dan ham yang mengandung token ke-i, serta $\boldsymbol{n}_{\boldsymbol{s}}$ dan $\boldsymbol{n}_{\boldsymbol{h}}$ berturut-turut adalah jumlah pesan yang tedapat pada kelas spam dan ham. Semakin sering suatu token muncul di kelas spam, nilai peluangnya akan semakin mendekati satu (Crossan 2009).

Untuk menghitung peluang suatu email masuk ke dalam kelas spam, metode Bayes Graham hanya menggunakan 15 token yang paling signifikan. Seberapa signifikan suatu token dalam menentukan hasil klasifikasi ditentukan dengan melihat selisih nilai $\mathbf{P}\left(\boldsymbol{S} \mid \boldsymbol{t}_{\boldsymbol{i}}\right)$ terhadap nilai peluang netral 0.5. Kelima belas token yang paling signifikan tersebut digunakan untuk menghitung peluang suatu email masuk ke dalam kelas spam dengan Persamaan 2.

$$
\mathrm{P}\left(\mathrm{S} \mid \mathrm{t}_{1}, \ldots, \mathrm{t}_{\mathrm{g}}\right)=\frac{\prod_{\mathrm{i}=1}^{15} \mathrm{P}\left(\mathrm{S} \mid \mathrm{t}_{\mathrm{i}}\right)}{\sum_{\mathrm{C}^{\prime} \epsilon(\mathrm{S}, \mathrm{H})} \prod_{\mathrm{i}=1}^{15} \mathrm{P}\left(\mathrm{C}^{\prime} \mid \mathrm{t}_{\mathrm{i}}\right)}
$$

Pesan akan dikategorikan sebagai spam jika nilai pada Persamaan 1 bernilai lebih besar dari 0.9 .

\section{Pengumpulan Data}

Tahap penelitian yang pertama adalah tahap pengumpulan data. Data yang digunakan sebagai data uji adalah korpus email dalam format asli, yang masih memiliki bagian header dan body. Data ini berisi campuran pesan yang sudah diberi label kelas, yaitu 'ham' dan 'spam' sesuai dengan kelasnya. Proses pemberian label kelas ini dilakukan secara manual.

\section{Pengujian Metode Training dan Metode Klasifikasi}

Pengujian dua metode training (TEFT dan TOE) dilakukan dengan cara mengukur akurasi kedua metode tersebut saat dipasangkan dengan metode Graham. Untuk menguji metode klasifikasi Bayes multinomial yang menggunakan atribut boolean digunakan metode yang sama dengan metode evaluasi pada penelitian Yerazunis (2004), yaitu:

1 Data uji berupa korpus email yang sudah diklasifikasikan ke dalam dua kelas, yaitu ' $h a m$ ' dan 'spam' disediakan. Setiap email diberi label sesuai dengan kelasnya. Data yang sudah diberi label tersebut kemudian digabungkan.

2 Data uji kemudian diacak sebanyak sepuluh kali. Setiap hasil pengacakan dicatat urutan pembacaannya sehingga seluruh metode yang diuji dievaluasi menggunakan acakan dan urutan pembacaan data yang sama.

3 Untuk setiap acakan, sebanyak $N$ data yang nantinya digunakan sebagai data testing akhir diambil.

4 Proses pengujian dilakukan sebanyak jumlah acakan, yaitu sepuluh kali pengujian.

5 Langkah 1 sampai dengan 4 akan menghasilkan data awal hasil pengujian berupa jumlah kesalahan klasifikasi dari 10 kali $N$ data uji.

Data awal hasil pengujian diolah lagi untuk mendapatkan tingkat akurasi hasil prediksi berupa jumlah true positive (TP), true negative (TN), false positive (FP), dan false negative (FN) seperti yang dapat dilihat pada Tabel 1.Hasil positif merujuk pada email yang diprediksikan masuk ke dalam kategori spam dan hasil negatif merujuk pada email yang diprediksikan masuk ke dalam kategori ham oleh filter. Kinerja masing-masing metode dievaluasi dengan melihat nilai dari spam recall dan ham recall. Spam recall adalah proporsi dari email spam yang berhasil diblok oleh filter, sedangkan ham recall menunjukkan proporsi dari email ham yang diloloskan oleh filter (Metsis et al. 2006). 


\begin{tabular}{|c|c|c|c|}
\hline & & \multicolumn{2}{|c|}{ Kelas Prediksi } \\
\hline & & Spam & Ham \\
\hline Kelas & Spam & $\mathrm{TP}$ & $\mathrm{FN}$ \\
\hline Sebenarnya & Ham & FP & $\mathrm{TN}$ \\
\hline
\end{tabular}

\section{Analisis Kesalahan Klasifikasi}

Setelah pengujian untuk metode training dan metode klasifikasi selesai dilakukan, penelitian selanjutnya berfokus pada analisis kesalahan klasifikasi. Pesan-pesan yang gagal diklasifikasikan ke dalam kelas yang benar, akan diteliti lebih lanjut untuk mencari penyebab kegagalan klasifikasi.

\section{HASIL DAN PEMBAHASAN}

\section{Pengumpulan Data}

Korpus yang digunakan pada penelitian ini adalah public email corpus yang disediakan oleh SpamAssasin yang diunduh dari alamat http://www.spamassassin.org/publiccorpus/ dengan kode prefiks 20030228. Korpus ini terdiri atas 6047 pesan email yang sudah diklasifikasikan sebelumnya secara manual. Perbandingan jumlah spam dan ham untuk data uji pada masing-masing acakan dapat dilihat pada Tabel 2 .

Tabel 2 Proporsi pesan spam untuk masing-masing acakan pengujian

\begin{tabular}{cccc}
\hline Pengacakan ke & Jumlah ham & Jumlah spam & Persen spam \\
\hline 1 & 529 & 221 & 29.46 \\
2 & 512 & 238 & 31.73 \\
3 & 514 & 236 & 31.46 \\
4 & 528 & 222 & 29.60 \\
5 & 518 & 232 & 30.93 \\
6 & 484 & 266 & 35.46 \\
7 & 518 & 232 & 30.93 \\
8 & 508 & 242 & 32.26 \\
9 & 529 & 221 & 29.46 \\
10 & 511 & 239 & 31.86 \\
\hline Jumlah & 5151 & 2349 & 31.32 \\
\hline
\end{tabular}

\section{Pemrosesan Dokumen}

Untuk fase latihan dan fase pengujian, setiap email diproses dengan teknik yang sama. Pemrosesan yang dilakukan terdiri atas empat tahap yaitu dekomposisi struktur email, pemilihan atribut, penyeragaman sistem karakter, dan tokenisasi. Secara garis besar, tahapan dekomposisi email yang dilakukan sebagai berikut:

1 Email dipecah ke dalam dua bagian utama, yaitu header dan body.

2 Komponen header dipecah lagi menjadi komponen-komponen yang lebih kecil sesuai dengan informasi yang dikandungnya.

3 Untuk komponen body, pesan yang terdiri atas beberapa bagian akan digabungkan menjadi satu. Jika pada email terdapat attachment, hanya informasi nama dan jenis file yang disertakan.

Setelah email dipecah menjadi komponen-komponen yang lebih kecil, tahapan selanjutnya adalah pemilihan komponen yang akan disertakan ke dalam proses klasifikasi. Tahapan ini berlaku terutama untuk bagian header dari email. 
Tidak semua komponen dari header dimasukkan ke dalam klasifikasi karena terdapat beberapa informasi pada header yang telah mengalami kerusakan ataupun telah diubah sebelumnya oleh pihak SpamAssasin sebagai penyedia data. Selain itu, terdapat komponen header yang hanya muncul di sebagian kecil dokumen. Komponen-komponen tersebut adalah informasi tambahan yang biasanya disertakan oleh klien email atau Mail Transfer Agent yang dilalui oleh email sebelum sampai ke tujuan (Tabel 3).

Tabel 3 Komponen header yang disertakan dalam proses klasifikasi

\begin{tabular}{ll}
\hline Nama & Keterangan \\
\hline Subject & Subjek dari pesan. \\
Sender & Nama dan alamat pengirim pesan. \\
return-path & Alamat pengembalian pesan jika terjadi bouncing (kondisi dimana alamat \\
& penerima tidak ditemukan). \\
$x$-mailer & Aplikasi yang digunakan oleh pengguna untuk mengirimkan pesan. \\
reply-to & Alamat yang digunakan untuk membalas pesan. \\
content-transfer-encoding & Metode content transfer encoding yang digunakan jika ada. \\
\hline
\end{tabular}

\section{Hasil Pengujian Metode Training}

Pengujian metode training dilakukan dengan cara memasangkan kedua metode tersebut pada filter spam yang menggunakan metode klasifikasi Bayes Graham. Pada metode TEFT, seluruh email yang dibaca akan dimasukkan ke dalam kelas yang benar setelah hasil dari klasifikasi diperoleh. Proses training ini dilakukan tanpa memperhatikan hasil klasifikasinya benar atau salah. Pada metode TOE, proses training hanya akan dilakukan jika terjadi kesalahan klasifikasi.

Jumlah FP dan FN per 7500 kali pengujian beserta ham recall dan spam recall dapat dilihat pada Tabel 4.

Tabel 4 Hasil pengujian metode training menggunakan teknik klasifikasi Graham

\begin{tabular}{lcc}
\hline & TEFT & TOE \\
\hline False Positive & 74 & 475 \\
False Negative & 50 & 67 \\
Spam Recall & 0.9786 & 0.9714 \\
Ham Recall & 0.9856 & 0.9079 \\
\hline
\end{tabular}

Hasil pengujian menggunakan metode Bayes Graham menunjukkan bahwa metode training TEFT memiliki tingkat akurasi yang lebih tinggi dibandingkan dengan metode training TOE. Perbedaan akurasi ini disebabkan oleh lebih banyaknya proses training yang dilakukan oleh metode TEFT dibandingkan dengan metode TOE. Proses training yang lebih banyak membuat metode TEFT menyimpan informasi yang lebih akurat mengenai karakteristik token-token dari kelas spam maupun ham dalam data hasil training. Walaupun perbedaan nilai spam recall hanya sebesar 0.0072 , namun perbedaan nilai ham recall antara kedua metode training tersebut cukup tinggi, yaitu 0.0777 .

Nilai ham recall berhubungan dengan tingkat false positive. Pada filter spam, overhead dari false positive lebih tinggi dibandingkan dengan false negative. Berdasarkan hal ini, perbedaan tingkat akurasi ini cukup signifikan untuk dipertimbangkan.

Karena proses training dilakukan untuk seluruh email yang masuk, TEFT membutuhkan waktu pengujian lebih lama dibandingkan dengan TOE. Hasil pengujian 
menunjukkan TEFT menghabiskan waktu sekitar 18\% lebih lama dibandingkan dengan TOE. Dengan demikian, meskipun TOE memiliki tingkat akurasi yang lebih rendah dibandingkan dengan TEFT, waktu pemrosesan yang dilakukan oleh TOE lebih singkat.

Perbedaan waktu antara kedua metode training ini dapat dibandingkan dengan memperhatikan perbedaan nilai spam recall dan ham recall untuk setiap tambahan waktu proses. Untuk spam recall, peningkatan kinerja per satuan waktu $(\boldsymbol{G S})$ dapat dihitung dengan Persamaan 3.

$$
\mathrm{GS}=\left|\frac{\mathrm{SR}_{\mathrm{TOE}}-\mathrm{SR}_{\mathrm{TEFT}}}{\mathrm{DW}}\right|
$$

dengan $\boldsymbol{S R}$ adalah nilai spam recall dan $\boldsymbol{D W}$ adalah persentase perbedaan waktu yang dihabiskan oleh kedua metode training. Dengan cara yang sama, peningkatan ham recall $(\boldsymbol{G H})$ untuk masing-masing metode training dapat dihitung dengan Persamaan 4.

$$
\mathrm{GH}=\left|\frac{\mathrm{HR}_{\mathrm{TOE}}-\mathrm{HR}_{\mathrm{TEFT}}}{\mathrm{DW}}\right|
$$

dengan $\boldsymbol{H R}$ adalah nilai ham recall untuk masing-masing metode training. Dibandingkan dengan metode TOE, metode TEFT dapat meningkatkan akurasi namun prosesnya lebih lambat. Dengan perhitungan pada Persamaan 3 dan 4, didapat bahwa penggunaan metode TEFT dibandingkan dengan TOE akan meningkatkan spam recall sebesar $0.04 \%$ untuk setiap $1 \%$ penambahan waktunya. Sementara untuk ham recall, peningkatan akurasi yang didapatkan adalah sebesar $0.43 \%$ untuk setiap $1 \%$ penambahan waktunya.

\section{Hasil Pengujian Metode Klasifikasi}

Proses pengujian metode klasifikasi dilakukan dengan menggunakan metode training TEFT. Jumlah FP dan FN per 7500 kali pengujian beserta nilai ham recall dan spam recall dapat dilihat pada Tabel 5.

Hasil pengujian menggunakan mode training TEFT menunjukkan bahwa metode Bayes Graham memiliki spam recall lebih tinggi dibanding metode Bayes multinomial dengan perbedaan nilai sebesar 0.0171 . Hasil sebaliknya terlihat pada ham recall dimana metode Bayes multinomial memiliki nilai yang lebih tinggi dengan perbedaan nilai sebesar 0.0150.

Tabel 5 Hasil pengujian metode klasifikasi dengan metode training TEFT dan TOE

\begin{tabular}{lcccc}
\hline & \multicolumn{2}{c}{ Metode TEFT } & \multicolumn{2}{c}{ Metode TOE } \\
\cline { 2 - 5 } & Graham & Multinomial & Graham & Multinomial \\
\cline { 2 - 5 } False Positive & 74 & 70 & 475 & 117 \\
False Negative & 50 & 67 & 67 & 55 \\
Spam Recall & 0.9786 & 0.9615 & 0.9714 & 0.9765 \\
Ham Recall & 0.9714 & 0.9864 & 0.9079 & 0.9773 \\
\hline
\end{tabular}

Pengujian dengan metode training TOE menunjukkan bahwa metode klasifikasi Bayes multinomial memiliki spam recall dan ham recall yang lebih tinggi dibandingkan dengan metode Bayes Graham dengan perbedaan masing-masing sebesar 0.0051 dan 0.0694.

\section{Analisis Kesalahan Pengenalan Ham (False Positive)}

Meskipun dalam proses klasifikasinya metode Bayes Graham mengalikan jumlah kemunculan token pada kelas ham dengan faktor bernilai 2, ternyata tingkat ham recall masih lebih rendah dibandingkan dengan ham recall dari metode Bayes multinomial. Lebih rendahnya ham recall dari metode Bayes Graham disebabkan oleh pemberian nilai 0.99 untuk token yang hanya pernah muncul di kelas spam. Dalam menentukan hasil klasifikasi, metode 
Bayes Graham hanya menggunakan 15 token yang paling signifikan. Jika email dari kelas ham mengandung token-token yang hanya muncul di kelas spam, proses klasifikasi akan didominasi oleh token-token spam karena token dengan peluang 0.99 memiliki selisih yang tinggi dari peluang netral 0.5.

Adapun karakteristik email yang menyebabkan false positive antara lain ialah:

Email ham yang mengandung tag HTML

Karakteristik seperti ini banyak ditemukan pada email yang berjenis newsletter. Karena data uji yang digunakan tidak memiliki email newsletter dalam jumlah yang cukup, tokentoken ham pada email tersebut tidak memiliki nilai $\mathbf{P}(\boldsymbol{H} \mid \boldsymbol{t})$ yang signifikan untuk mengimbangi token-token spam yang ada. Akibatnya terjadi false positive dalam proses filtering yang dilakukan.

Newsletter resmi yang memiliki isi bertema promosi

Selain pengaruh tag HTML, false positive juga banyak dipengaruhi oleh isi dari email itu sendiri. Meskipun newsletter dikirimkan dengan persetujuan penerimanya, isi dari newsletter seringkali berbau promosi dan menggunakan kata-kata yang digunakan pada email spam. Pada kasus seperti ini, baik metode Graham maupun multinomial, keduanya mengalami kesulitan dalam menentukan kelas yang benar.

Email ham yang memiliki beberapa format multipart-alternative

Email dengan format multipart-alternative memungkinkan email dikirimkan dalam beberapa versi sekaligus. Sebagai contoh, jika aplikasi klien memiliki kapabilitas untuk membaca dokumen HTML, maka akan ditampilkan versi email yang menggunakan tag HTML. Namun jika tidak, akan ditampilkan versi yang hanya menggunakan teks biasa.

Kesalahan lain

Selain beberapa butir yang sudah disebutkan, terdapat beberapa faktor lain yang menyebabkan false positive meskipun tidak dalam jumlah banyak. Email yang menggunakan token berhuruf kapital dalam jumlah banyak, seperti email berisi peringatan cuaca buruk, sering salah diklasifikasikan sebagai spam karena kata-kata dalam huruf kapital banyak ditemukan pada email spam. Email yang dikirimkan oleh aplikasi auto-responder beberapa kali salah diklasifikasikan sebagai spam karena isinya yang pendek dan mengandung katakata yang umum ditemukan pada email spam seperti 'call', 'contact', dan 'respond'. Selain itu, email pendek yang hanya berisikan URL juga kadang salah diklasifikasikan sebagai spam karena URL lebih banyak ditemukan pada email spam.

\section{Analisis Kesalahan Pengenalan Spam (False Negative)}

Hasil pengujian terhadap kedua metode klasifikasi tidak membuahkan kesimpulan mengenai metode mana yang memiliki tingkat false negative lebih tinggi. Selanjutnya, karakteristik pesan spam yang berhasil lolos dari proses filtering dibahas.

Email spam yang kebetulan memiliki isi seperti ham.

Pesan-pesan ham pada data uji didominasi oleh pesan dari mailing list bertemakan teknologi informasi. Pesan-pesan spam yang memiliki tema sangat berbeda seperti obat ataupun judi akan mudah dikenali oleh filter spam, namun jika spam yang dikirim ternyata bertemakan teknologi informasi, kata-kata yang terkandung di dalamnya akan memiliki karakteristik yang mirip dengan mayoritas email ham. Akibatnya, filter akan salah mengklasifikasikan email spam tersebut sebagai ham.

Email yang menggunakan huruf non-latin.

Pemrosesan tokenisasi pada email berkarakter latin dan berkarakter non-latin memiliki sedikit perbedaan. Pada email berkarakter latin, dengan satu karakter pemisah token saja yaitu spasi, email sudah dapat dipecahkan menjadi token-token dengan cukup baik. Pada tulisan dimana karakternya tidak menggunakan spasi sebagai pemisah token, proses tokenisasi biasa tidak akan menghasilkan token-token yang sesuai. Selain itu, email dengan huruf non-latin 
pada data pengujian jumlahnya sangat sedikit. Kurangnya data latih untuk token-token yang ada menyebabkan token tersebut memiliki nilai peluang yang cenderung netral, yaitu 0.5. Khusus pada metode Graham, batas nilai peluang suatu email untuk masuk ke dalam kelas spam adalah 0.9 sehingga email-email yang dipenuhi dengan token netral akan masuk ke dalam kelas ham.

Email yang isinya gagal di-decode.

Beberapa email yang menggunakan character-encoding maupun content-transferencoding khusus gagal di-decode. Hal ini disebabkan oleh kurangnya pustaka pembaca email yang digunakan atau kesalahan format pada email. Kegagalan proses decode menyebabkan isi dari email hanya muncul sebagian atau tidak muncul sama sekali sehingga proses klasifikasi didominasi oleh token-token dari header.

\section{SIMPULAN}

Pengujian menggunakan metode klasifikasi Bayes Graham menunjukkan metode training TEFT memiliki akurasi yang lebih tinggi dibandingkan dengan metode TOE, terutama pada ham recall yang memiliki perbedaan nilai mencapai 0.0777. Pengujian menggunakan kedua metode training menunjukkan metode Bayes multinomial memiliki akurasi yang lebih tinggi dibandingkan dengan metode Bayes Graham, kecuali untuk spam recall pada pengujian dengan metode training TEFT ketika metode Bayes Graham memiliki nilai spam recall yang lebih tinggi.

Kegagalan pengenalan ham (false positive) disebabkan oleh penggunaan token-token yang umum pada email spam di kelas ham seperti email dengan tag HTML, sedangkan kegagalan pengenalan spam (false negative) disebabkan oleh isi dari email spam yang dikirim kebetulan sama dengan tema dari email pengguna.

\section{DAFTAR PUSTAKA}

Crossan J. 2009. Naïve Bayes classification in spam filtering.

Graham P. 2002. A plan for spam [Internet]. [diunduh 2009 Des 14]. Tersedia pada: http://paulgraham.com/spam.html.

Graham P. 2003. Stopping spam [Internet]. [diunduh 2009 Des 14]. Tersedia pada: http://paulgraham.com/stopspam.html.

Metsis V, Androutsopoulos I, Paliouras G. 2006. Spam filtering with naïve Bayes-which naïve Bayes? Di dalam: Third Conference on Email and AntiSpam (CEAS) 2006; 2006 Jul 27-28; Mountain View, Amerika Serikat. 17:28-69.

Pantel P, Lin D. 1998. SpamCop: a spam classification and organization program. Di dalam: Proceedings of AAAI-98 on Learning for Text Categorization; 1998 Jul 26-27; Madison, Amerika Serikat. hlm 95-98.

Sahami M, Dumais S, Heckerman D, Horvitz E. 1998. A Bayes approach to filtering junk email. Di dalam: Proceedings of AAAI-98 on Learning for Text Categorization; $1998 \mathrm{Jul}$ 26-27; Madison, Amerika Serikat. hlm 98-105.

Schneider KM. 2004. On word frequency information and negative evidence in naïve Bayes text classification. Di dalam: Advances in Natural Language Processing. Berlin (DE): Springer. hlm 474-485.

Spamhaus. 2009. The definition of spam [Internet]. [diunduh 2009 Des 29]. Tersedia pada: http://www.spamhaus.org/definition.html.

Yerazunis WS. 2004. The spam-filtering accuracy plateau at 99.9 percent accuracy and how to get past it. Di dalam: Proc. MIT Spam Conference 2004. 